\title{
Reversible Hypertensive Encephalomyelopathy Syndrome
}

\section{Reversibl Hipertansif Ensefalomiyelopati Sendromu}

Keywords: Posterior reversible encephalopathy syndrome, spinal cord, hypertension

Anahtar Kelimeler: Posterior reversibl ensefalopati sendromu, spinal kord, hipertansiyon

\section{Dear Editor,}

A 21-year-old female patient presented with symptoms of vision loss, headache, nausea, and vomiting. Her blood pressure was $260 / 120 \mathrm{mmHg}$, and her visual acuity was 20/200 on the left and total loss on the right. Fundoscopy revealed advanced thinning of the arteries, decreased artery/vein ratio, cotton wool spot, exudate, and hemorrhage areas (grade IV hypertensive retinopathy). The patient was admitted to the Nephrology Clinic and oral and parenteral antihypertensive treatment was started. No abnormalities were detected in the examinations for secondary hypertension. Brain magnetic resonance imaging (MRI) revealed hyperintense signal changes in the pons, medulla oblongata and cerebellar vermis on $\mathrm{T} 2$ and fluid-attenuated inversion recovery (FLAIR)-weighted images (Figure 1). Cervical sagittal T2weighted images showed T2 hyperintense signal change from the craniocervical junction to the level of $\mathrm{C} 7$ leading to cord expansion (Figure 2). Axial T2-weighted images showed hyperintense signal changes in the central cord (Figure 3). The patient was diagnosed as having posterior reversible encephalopathy syndrome with spinal cord involvement (PRES-SCI). The patient's vision loss partially improved over time, and the MRI findings disappeared completely after one month.

PRES is a reversible clinicoradiologic entity clinically characterized by encephalopathy, seizures, headache, visual disturbances and focal neurological symptoms, and radiologically characterized by parietooccipital involvement and subcortical vasogenic edema (1). The most common cause is severe acute

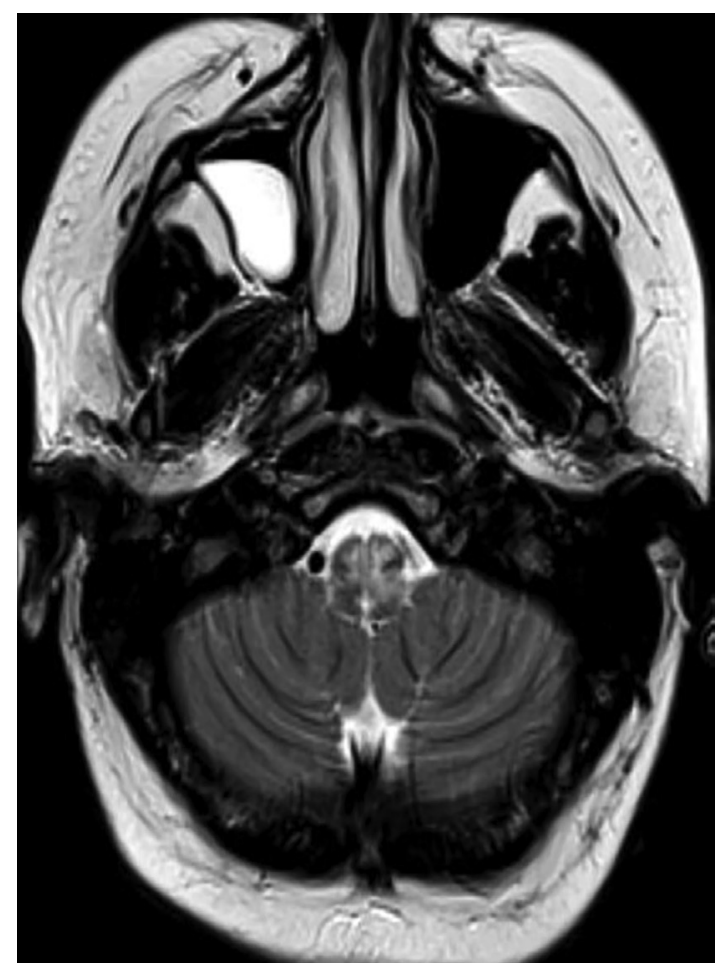

Figure 1. Central hyperintense signal change in the medulla oblongata on T2-weighted axial brain magnetic resonance image

Address for Correspondence/Yazışma Adresi: Özlem Kayım Yıldız MD, Cumhuriyet University Faculty of Medicine, Department of Neurology, Sivas, Turkey Phone: +903462580000 E-posta: ozlemkayim@yahoo.com ORCID: orcid.org/0000-0002-0382-9135

Received/Geliş Tarihi: 28.02.2019 Accepted/Kabul Tarihi: 03.04.2019

Presented in: This article was presented as e-poster in $5^{\text {th }}$ National Neurology Congress.

${ }^{\circ}$ Copyright 2020 by Turkish Neurological Society

Turkish Journal of Neurology published by Galenos Publishing House. 


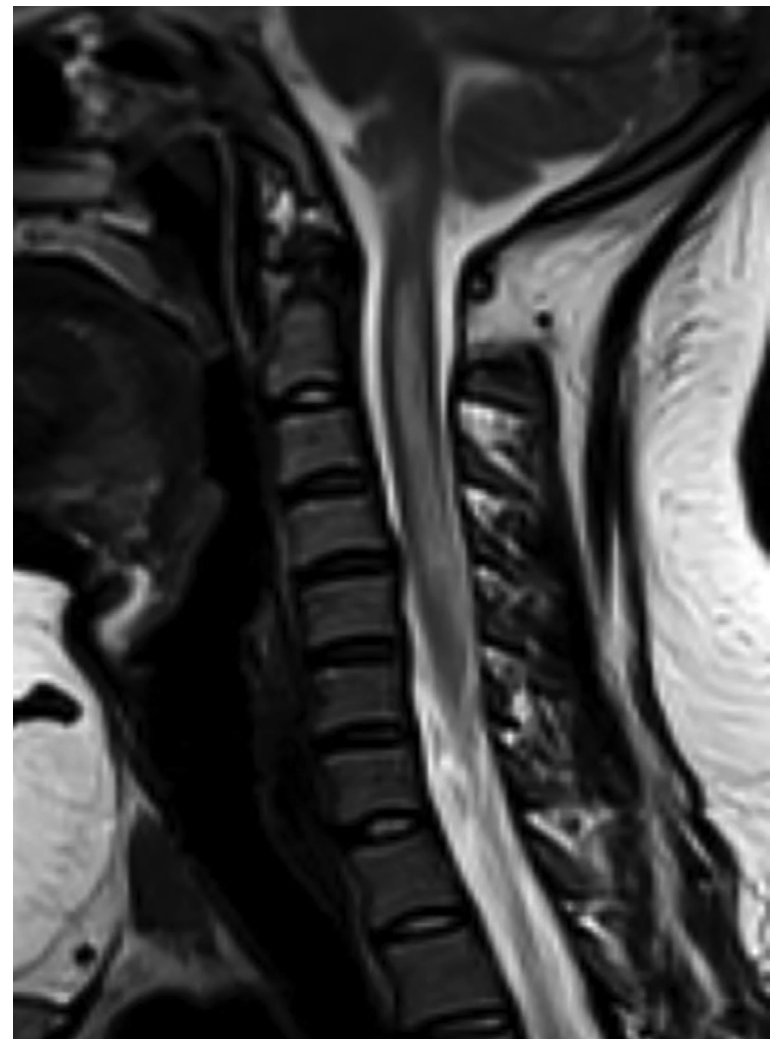

Figure 2. Longitudinal cord hyperintensity on T2-weighted sagittal cervical spinal magnetic resonance image

hypertension (2). The pathophysiologic mechanism is thought to be hypertension-induced blood-brain barrier dysfunction and cerebral autoregulation deficiency (3). The lack of sympathetic innervation in the posterior circulation explains the greater involvement of the posterior brain regions.

As a result of the disruption of the vascular autoregulatory mechanism in the spinal cord, a condition called PRES-SCI or reversible hypertensive encephalomyelopathy may develop (1). This condition, characterized by excessive elevation of blood pressure, grade IV hypertensive retinopathy, and longitudinally extending T2 hyperintensity to the cervicomedullary junction, has been reported in very few patients to date (1). PRES-SCI is thought to develop by the same mechanism as cerebral PRES because the cervical spinal cord is fed by the spinal arteries that are the branches of vertebral arteries with low sympathetic innervation. Severe hypertension is present in $70-80 \%$ of patients with classic PRES, whereas all patients with spinal PRES are hypertensive at presentation and usually show symptoms of hypertensive encephalopathy. In addition, unlike classic PRES, almost all patients with PRES-SCI have vision loss associated with hypertensive retinopathy. PRES-SCI is characterized radiologically by longitudinal T2 hyperintensity involving the central cord, often extending to the cervicomedullary junction. In contrast to cerebral

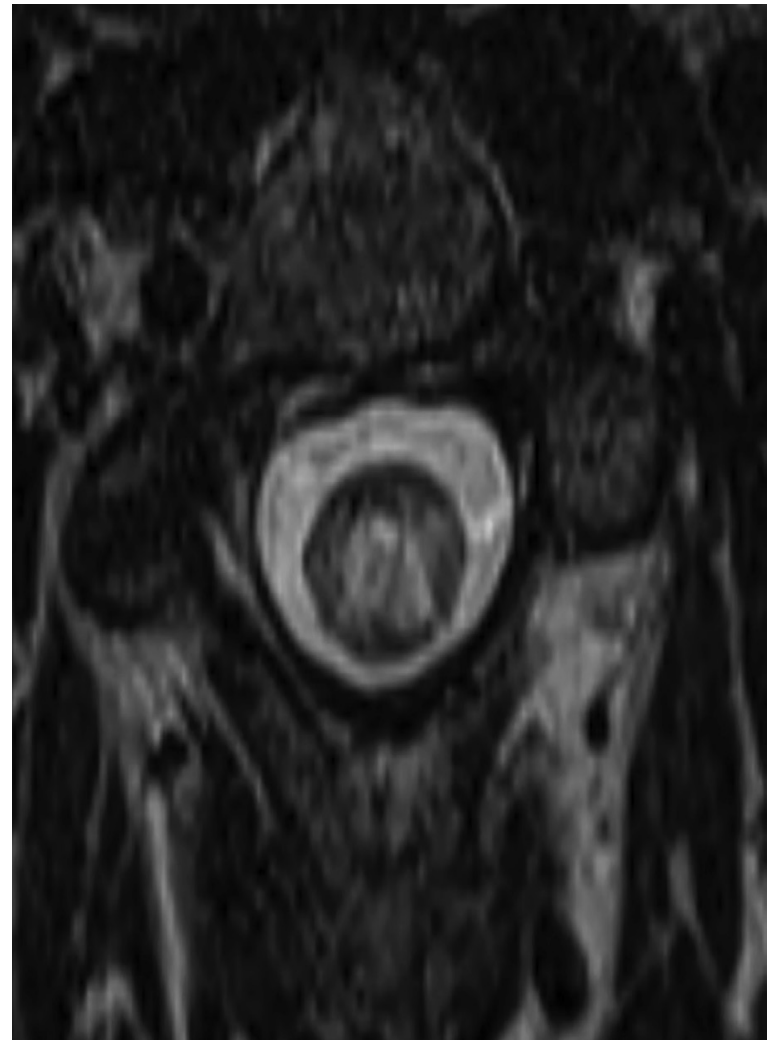

Figure 3. Hyperintense signal changes in the central cord on T2weighted axial cervical spinal magnetic resonance image

PRES, gray matter (cord central) involvement is prominent. Although the radiologic findings are severe, clinical symptoms of spinal cord involvement are absent/mild. This 'clinicoradiologic dissociation' is extremely valuable in the differentiation from myelitis. Most patients have classic radiological findings of PRES in addition to cord involvement; only a few patients have brain stem and cord involvement. It is characterized by clinicoradiologic complete recovery (1).

\section{Ethics}

Informed Consent: It was not taken.

Peer-review: Internally peer-reviewed.

Financial Disclosure: The author declared that this study received no financial support.

\section{References}

1. de Havenon A, Joos Z, Longenecker L, Shah L, Ansari S, Digre K. Posterior reversible encephalopathy syndrome with spinal cord involvement. Neurology 2014;83:2002-2006.

2. Servillo G, Bifulco F, De Robertis E, et al. Posterior reversible encephalopathy syndrome in intensive care medicine. Intensive Care Med 2007;33:230-236.

3. Fugate JE, Rabinstein AA. Posterior reversible encephalopathy syndrome: clinical and radiological manifestations, pathophysiology, and outstanding questions. Lancet Neurol 2015;14:914-925. 